\title{
Shear bond strength of a flash-free orthodontic adhesive system after thermal aging procedure
}

\author{
Carlos González-Serrano ${ }^{1}$, Eugenia Baena ${ }^{2}$, María-Victoria Fuentes ${ }^{2}$, Alberto Albaladejo ${ }^{3}$, Manuel \\ Míguez-Contreras ${ }^{4}$, Manuel 0 . Lagravère ${ }^{5}$, Laura Ceballos ${ }^{6}$
}

${ }^{1} \mathrm{PhD}$ Student, Area of Stomatology, Health Sciences Faculty, Rey Juan Carlos University, Alcorcón, Madrid, Spain

${ }^{2}$ Assistant Professor, Area of Stomatology, Health Sciences Faculty, Rey Juan Carlos University, Alcorcón, Madrid, Spain

${ }^{3}$ Associate Professor, Department of Surgery, Faculty of Medicine, University of Salamanca, Salamanca, Spain

${ }^{4}$ Assistant Professor, Department of Stomatology, Health Sciences Faculty, Alfonso X el Sabio, Madrid, Spain

${ }^{5}$ Associate Professor, School of Dentistry, Faculty of Medicine \& Dentistry, University of Alberta, Edmonton, Canada

${ }^{6}$ Full Professor, Area of Stomatology, Health Sciences Faculty, Rey Juan Carlos University, Alcorcón, Madrid, Spain

Correspondence:

Faculty of Medicine and Dentistry

School of Dentistry

ECHA 5-524, 11405-87 Avenue, Edmonton

Alberta T6G 1C9, Canada

mlagravere@ualberta.ca

Received: $31 / 12 / 2018$

Accepted: 14/01/2019

González-Serrano C, Baena E, Fuentes MV, Albaladejo A, Míguez-Contreras M, Lagravère MO, Ceballos L. Shear bond strength of a flash-free orthodontic adhesive system after thermal aging procedure. J Clin Exp Dent. 2019;11(8):e679-679.

http://www.medicinaoral.com/odo/volumenes/v11i8/jcedv11i8p679.pdf

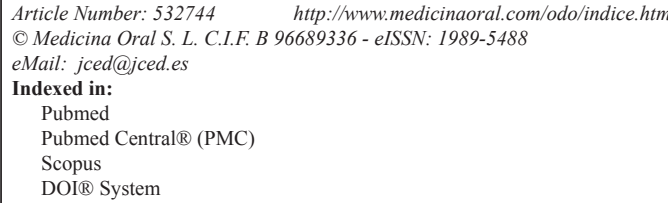

\begin{abstract}
In this article by Carlos and colleagues (J Clin Exp Dent. 2019 Feb 1;11(2):e154-61), there is an error in the Material and Methods of the abstract. The correct Material and Methods of the abstract is: Material and Methods: A total of 120 human premolars were randomly divided into two groups $(n=60)$ according to the orthodontic adhesive used: APC Flash-Free Adhesive Coated Appliance System (APC FF) or Transbond PLUS Color Change Adhesive (TP), as control. A SBS test was performed and ARI value for each specimen was also assessed. Results were analyzed by two-way ANOVA and Tukey's Chi-square test $(\mathrm{p}<0.05)$.
\end{abstract}

